\title{
Paracetamol and cyclooxygenase inhibition: is there a cause for concern?
}

\author{
Burkhard Hinz, ${ }^{1}$ Kay Brune ${ }^{2}$
}

${ }^{1}$ Institute of Toxicology and Pharmacology, University of Rostock, Rostock, Germany ${ }^{2}$ Department of Experimental and Clinical Pharmacology and Toxicology, Friedrich Alexander University Erlangen-Nürnberg, Erlangen, Germany

\section{Correspondence to Professor Burkhard Hinz, Institute of Toxicology and Pharmacology, University of Rostock, Schillingallee 70, D-18057 Rostock \\ Germany; \\ burkhard.hinz@med. \\ uni-rostock.de}

Accepted 10 September 2011 Published Online First 28 October 2011

\begin{abstract}
Paracetamol is recommended as first-line therapy for pain associated with osteoarthrosis and is one of the most widely used over-the-counter analgesic drugs worldwide. Despite its extensive use, its mode of action is still unclear. Although it is commonly stated that paracetamol acts centrally, recent data imply an inhibitory effect on the activity of peripheral prostaglandin-synthesising cyclooxygenase enzymes. In this context paracetamol has been suggested to inhibit both isoforms in tissues with low levels of peroxide by reducing the higher oxidation state of cyclooxygenase enzymes. Two recent studies have also demonstrated a preferential cyclooxygenase 2 (COX-2) inhibition by paracetamol under different clinically relevant conditions. This review attempts to relate data on paracetamol's inhibitory action on peripheral cyclooxygenase enzymes to the published literature on its anti-inflammatory action and its hitherto underestimated side-effects elicited by cyclooxygenase inhibition. As a result, a pronounced COX-2 inhibition by paracetamol is expected to occur in the endothelium, possibly explaining its cardiovascular risk in epidemiological studies. A careful analysis of paracetamol's cardiovascular side-effects in randomised studies is therefore strongly advised. On the basis of epidemiological data showing an increased gastrointestinal risk of paracetamol at high doses or when co-administered with classic cyclooxygenase inhibitors, paracetamol's long-term gastrointestinal impact should be investigated in randomised trials. Finally, paracetamol's fast elimination and consequently short-lived COX-2 inhibition, which requires repetitive dosing, should be definitely considered to avoid overdosage leading to hepatotoxicity.
\end{abstract}

Paracetamol is one of the most widely used overthe-counter antipyretic and analgesic drugs worldwide. It is recommended as first-line therapy for pain associated with osteoarthrosis. ${ }^{1}$ Although discovered over 100 years ago and extensively used for over 50 years, its mode of action is still a matter of debate. For more than three decades it was commonly stated that paracetamol acts centrally and is at best a weak inhibitor of prostaglandin synthesis by cyclooxygenase 1 (COX-1) and cyclooxygenase 2 (COX-2). ${ }^{2}$ This concept is based on early work by Flower and $V_{a n} e^{3}$ who showed that prostaglandin production in the brain is 10 times more sensitive to inhibition by paracetamol than that in the spleen. Later it turned out that paracetamol elicits no measurable inhibition of prostaglandin formation in broken cell preparations, but a profound suppression in intact cells (comprehensively reviewed in Graham and Scott). ${ }^{4}$ Attempts to explain the pharmacological action of paracetamol as inhibition of a central cyclooxygenase isoform, derived from the same gene as COX-1 and referred to as cyclooxygenase $3,{ }^{5}$ have meanwhile been rejected. ${ }^{6}$

Instead, several data published during the past few years suggest a tissue-dependent inhibitory effect of paracetamol on the activity of both central and peripheral cyclooxygenase enzymes. In view of the current debate concerning the safety of cyclooxygenase inhibitors, these findings raise several questions with respect to hitherto underestimated cyclooxygenase-dependent side-effects of paracetamol, which has long been regarded as a safe alternative to traditional non-steroidal anti-inflammatory drugs (NSAID) and latterly also to selective COX-2 inhibitors. In the present review attempts have been undertaken to relate the data on the cyclooxygenase inhibitory potency of paracetamol to the published literature on its anti-inflammatory action and, more importantly, side-effects possibly related to inhibition of cyclooxygenase enzymes.

\section{MODE OF CYCLOOXYGENASE INHIBITION}

The pathway leading to the generation of prostaglandins has been elucidated in detail. Within this process, the cyclooxygenase enzyme (also referred to as prostaglandin $\mathrm{H}$ ( $\mathrm{PGH}$ ) synthase) catalyses the first step of the synthesis of prostanoids by converting arachidonic acid into $\mathrm{PGH}_{2}$, which is the common substrate for specific prostaglandin synthases. The enzyme is bifunctional, with fattyacid cyclooxygenase activity (catalysing the conversion of arachidonic acid to prostaglandin $G_{2}$ $\left(\mathrm{PGG}_{2}\right)$ ) and prostaglandin hydroperoxidase activity (catalysing the conversion of $\mathrm{PGG}_{2}$ to $\mathrm{PGH}_{2}$ ) (figure 1).

Whereas traditional NSAID and selective COX-2 inhibitors inhibit cyclooxygenase by competing with arachidonic acid for entering the cyclooxygenase reaction, ${ }^{78}$ paracetamol has been suggested to act as a reducing agent within the peroxidase site. In brief, paracetamol quenches a protoporphyrin radical cation. The latter generates the tyrosine radical in the cyclooxygenase site that is responsible for catalysing the oxygenation of arachidonic acid. ${ }^{9} 10$

In view of the fact that hydroperoxides oxidise the porphyrin within the peroxidase site, cyclooxygenase inhibition by paracetamol is hampered by high peroxide levels. Accordingly, Boutaud et a $1^{10}$ showed that high levels of peroxides overcome the inhibitory effect of paracetamol on the cyclooxygenase enzymes in diverse cells. As such, 12-hydroperoxyeicosatetraenoic acid, a major product of platelets, completely reversed the inhibitory action of paracetamol on COX-1. Likewise, the addition of peroxides to interleukin 1-stimulated endothelial cells (as a model of a peroxide-enriched 


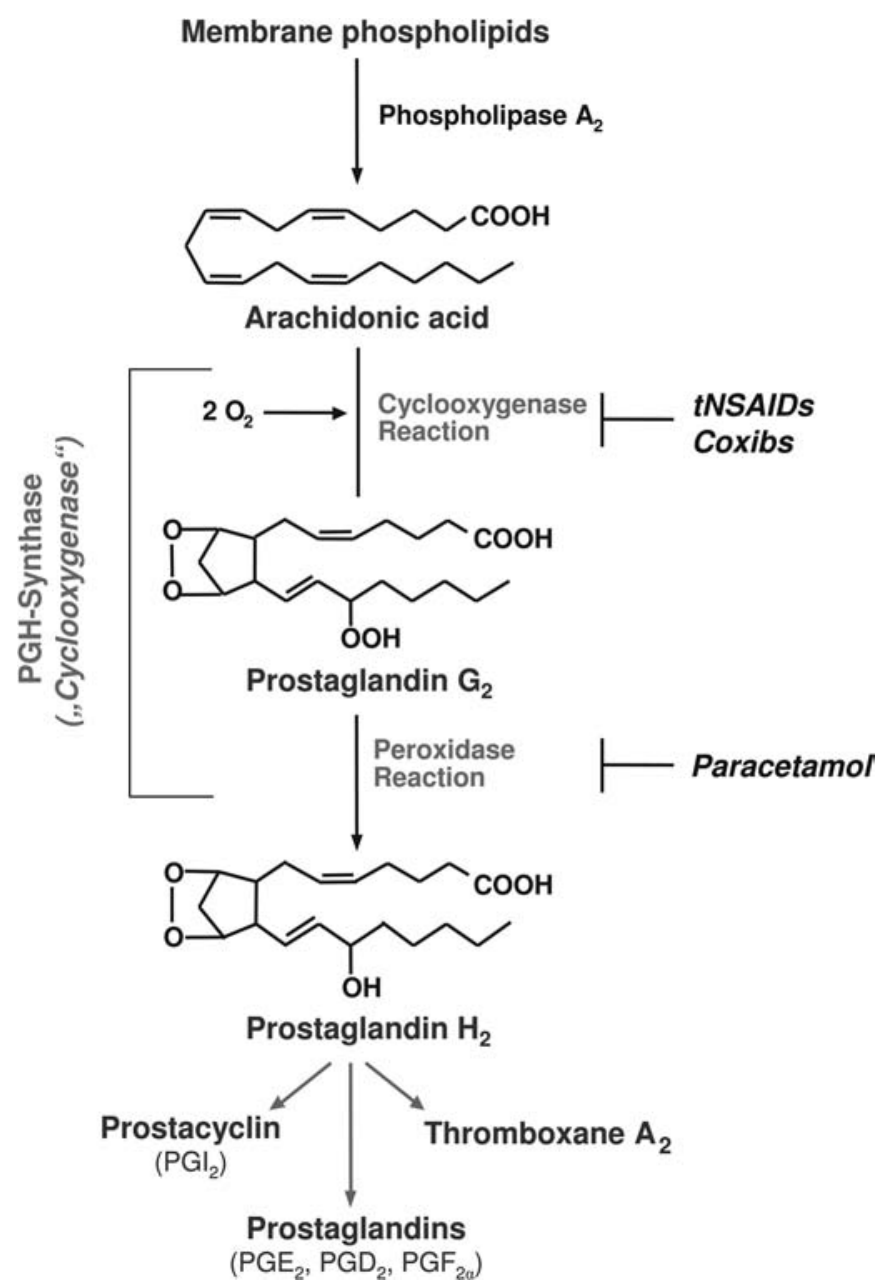

Figure 1 Biochemical function of the cyclooxygenase enzyme and pharmacological targets within its two activity sites. Paracetamol acid released from membrane phospholipids by the enzyme phospholipase $A_{2}$ is converted by cyclooxygenase (also referred to as prostaglandin (PG) $\mathrm{H}$ synthase) to $\mathrm{PGH}_{2}$, the common substrate for specific prostanoid synthases. Cyclooxygenase is bifunctional, with fatty-acid cyclooxygenase activity (catalysing the conversion of arachidonic acid to $P G_{2}$ ) and prostaglandin hydroperoxidase activity (catalysing the conversion of $\mathrm{PGG}_{2}$ to $\mathrm{PGH}_{2}$ ). Traditional non-steroidal anti-inflammatory drugs (tNSAID) and selective cyclooxygenase 2 inhibitors (coxibs) compete with arachidonic acid for entering the cyclooxygenase reaction. In contrast, paracetamol may act as a reducing agent within the peroxidase site by quenching a radical that is responsible for the propagation of the cyclooxygenase reaction.

inflammatory tissue) abrogated COX-2 inhibition by paracetamol, whereas paracetamol inhibited COX-2 in the absence of peroxide at concentrations relevant to its antipyretic effect.

\section{PREFERENTIAL COX-2 INHIBITION BY PARACETAMOL}

Two recent studies have suggested a preferential COX-2 inhibitory action of paracetamol under different clinically relevant conditions.

In the first of these studies, Hinz et al ${ }^{11}$ using the ex-vivo human whole blood assay were able to show that oral administration of $1 \mathrm{~g}$ paracetamol to human volunteers inhibits blood monocyte COX-2 by up to $80 \%$ (figure 2). According to Huntjens et al ${ }^{12}$ ex-vivo COX-2 inhibition in the whole blood assay by approximately $80 \%$ is expected to result in analgesia due to the fact that the analgesic therapeutic plasma concentration of a cyclooxygenase inhibitor correlates with its inhibitory concentration (IC) 80 (the concentration that leads to $80 \%$ inhibition) on COX-2 in the human whole blood assay. However, due to its short halflife (approximately $2 \mathrm{~h}$ ) paracetamol elicits a short-lived COX-2 inhibition only (figure 2). Thus, repetitive 1-g doses of paracetamol have to be administered to provide a permanent $80 \%$ COX-2 inhibition necessary for pain relief. This fact has to be considered to avoid overdosages with this drug.

By contrast, a greater than $95 \%$ COX-1 blockade that would be relevant for the inhibition of platelet function ${ }^{13}$ was not achieved (figure 2). Further experiments revealed that paracetamol elicits the most pronounced COX-2 inhibition in human whole blood when compared with the recombinant enzyme or freshly prepared human monocytes, ${ }^{11}$ thus confirming the dependence of its potency as a COX-2 inhibitor on the oxidant/antioxidant status of the surrounding system. As a matter of fact, human plasma comprising various enzymatic and non-enzymatic antioxidant components may provide favourable conditions in this respect. ${ }^{14}$

In another study using a clinical model of tissue injury and acute inflammation, outpatients received $1 \mathrm{~g}$ paracetamol before surgical removal of two impacted mandibular third molars and microdialysis was performed to collect inflammatory transudate from the surgical site for the measurement of COX-1 and COX2-dependent prostanoid levels at the site of injury. ${ }^{15}$ Again, paracetamol was revealed as a selective inhibitor of COX-2dependent prostaglandin $\mathrm{E}_{2}\left(\mathrm{PGE}_{2}\right)$ formation.

\section{INFLAMMATION}

Most pharmacological reference books depict paracetamol as a 'pure' analgesic without any anti-inflammatory activity. This claim is largely based on early work showing that paracetamol does not suppress serious inflammation associated with rheumatoid arthritis. ${ }^{16} 17$ This lack of effect can now be explained by the high extracellular concentrations of arachidonic acid and peroxide in the inflamed tissue, both of which diminish the effect of paracetamol on prostaglandin synthesis. ${ }^{4} 910$ In line with this notion paracetamol does not decrease the concentration of diverse prostanoids in the synovial fluid of patients with rheumatoid arthritis. ${ }^{18}$ On the other hand, paracetamol decreases tissue swelling following oral surgery in humans, with activity similar to that of ibuprofen, ${ }^{19} 20$ implying that the drug is not devoid of any anti-inflammatory action. Moreover, the abovecited study ${ }^{15}$ implies a significant impact of COX-2 inhibition to this response. In addition, a peripheral anti-inflammatory action is supported by several experimental studies showing paracetamol to be an inhibitor of nociception and oedema in the rat carrageenan footpad model, ${ }^{21} 22$ an inflammatory condition critically dependent on COX-2-derived prostaglandins. ${ }^{23}$ Therefore, the notion that paracetamol has only weak anti-inflammatory properties rather than causing no anti-inflammatory action at all appears to be more favourable.

\section{CARDIOVASCULAR SIDE-EFFECTS}

A permanent blockade of COX-2-dependent prostaglandins including prostacyclin and $\mathrm{PGE}_{2}$ is currently the most plausible explanation for the cardiovascular hazard conferred by traditional NSAID and selective COX-2 inhibitors. ${ }^{24} 25$ In this context, a long-term increase in blood pressure has been proposed to underlie cardiovascular side-effects occurring after the prolonged use of these compounds. In contrast to the inflamed tissue, endothelial cells possess low levels of peroxide making an undisturbed COX-2 inhibition by paracetamol possible. ${ }^{10}$

In line with this notion, paracetamol tested at a $70 \mu \mathrm{M}$ concentration was found to inhibit cyclooxygenase activity in human 
A

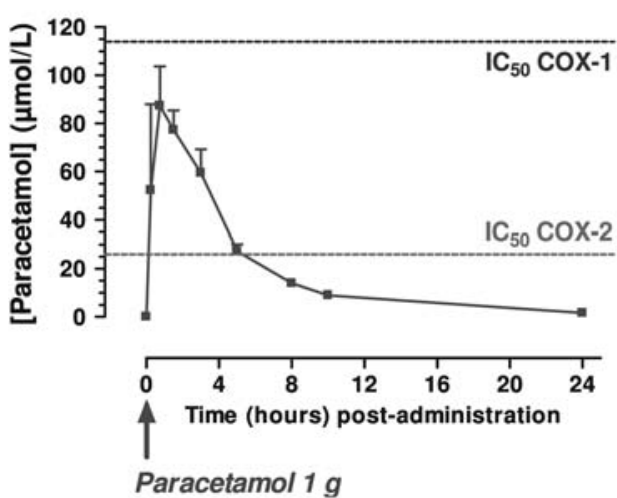

B

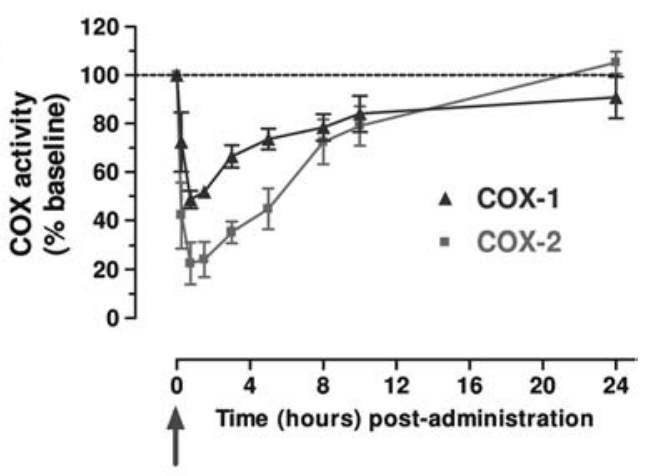

Paracetamol $1 \mathrm{~g}$

Figure 2 Plasma concentrations of paracetamol (A) and ex-vivo inhibition of cyclooxygenase 1 (COX-1) and cyclooxygenase 2 (COX-2) activity (B) following oral administration of $1 \mathrm{~g}$ paracetamol to five volunteers (data are from Hinz et al). ${ }^{11}$ Peripheral venous blood samples were taken from each subject immediately before and at specified time points postadministration. For the determination of ex-vivo COX-1 activity, whole blood samples without anticoagulant were incubated for $1 \mathrm{~h}$ at $37^{\circ} \mathrm{C}$ immediately after blood sampling. Subsequently, serum thromboxane $\mathrm{B}_{2}$ levels were determined as the index of COX-1 activity. In the case of COX-2, heparinised whole blood samples were incubated with lipopolysaccharide (10 $\mu \mathrm{g} / \mathrm{ml})$ and aspirin $\left(10 \mu \mathrm{g} / \mathrm{ml}\right.$; prevents a contribution of platelet COX-1) for $24 \mathrm{~h}$ at $37^{\circ} \mathrm{C}$. Afterwards, plasma levels of prostaglandin $\mathrm{E}_{2}$ were determined as the index of COX-2 activity. Values are means \pm SEM. The inhibitory concentration $\left(I C_{50}\right)$ values in the left figure are based on in-vitro experiments.

Table 1 Risk of cardiovascular events (non-fatal myocardial infarction, fatal coronary heart disease, non-fatal and fatal stroke) according to frequency of analgesic use and analgesic dose

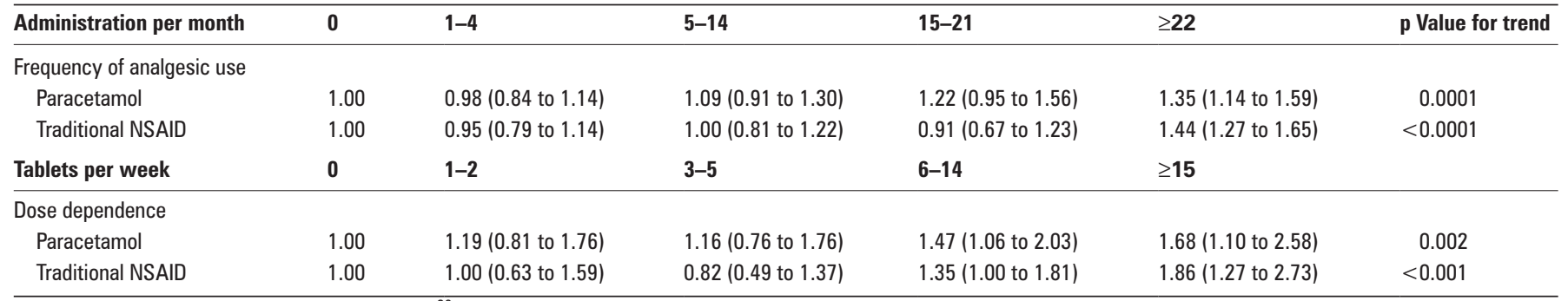

Data are the results of a prospective cohort study ${ }^{36}$ on 70971 women (aged 44-69 years at baseline, free of a known cardiovascular disease or cancer) that investigated the influence of paracetamol and traditional non-steroidal anti-inflammatory drugs (NSAID) on the risk of major cardiovascular events (non-fatal myocardial infarction, fatal coronary heart disease, non-fatal and fatal stroke) during a 12-year follow-up. Data are multivariate RR. Numbers in brackets are $95 \% \mathrm{Cl}$.

umbilical vein endothelial cells. ${ }^{26}$ In addition, oral administration of $500 \mathrm{mg}$ paracetamol was shown to reduce the urinary excretion of 2,3-dinor 6-keto prostaglandin $\mathrm{F}_{1 \alpha}\left(\mathrm{PGF}_{1 \alpha}\right)$, a stable, inactive metabolite of the major endothelium-derived COX-2 product prostacyclin. ${ }^{27}$ Likewise, a $50 \%$ reduction in the urinary excretion of this metabolite has been reported in pregnant women after the ingestion of $1 \mathrm{~g}$ paracetamol. ${ }^{26} \mathrm{It}$ is noteworthy that paracetamol use during pregnancy has been suggested to be associated with an increased risk of pre-eclampsia and thromboembolic disorders-diseases in which a reduction of prostacyclin during pregnancy has been postulated to play a role. ${ }^{28-31}$

In addition to these reports, inhibition of the lipopolysaccharideinduced $\mathrm{PGE}_{2}$ synthesis measured ex vivo in whole blood has been shown to correspond to the inhibition of the urinary excretion of 2.3-dinor 6-keto $\mathrm{PGF}_{1 \alpha}{ }^{32} \mathrm{On}$ the basis of this and other findings, ex-vivo COX-2 measurements from whole blood have been suggested as a potential surrogate to estimate the cardiovascular risk of a certain cyclooxygenase inhibitor. ${ }^{25} 3334$ In view of the up to $80 \%$ COX-2 inhibition by paracetamol in the exvivo whole blood assay (figure 2), a comparable effect in the endothelium is expected to confer a cardiovascular risk.

In fact, epidemiological data suggest that such a concern is justified: Regarding the effects of paracetamol on blood pressure, two prospective cohort studies among younger and older women from the Nurses' Health Studies found that regular consumption of paracetamol at over $500 \mathrm{mg} /$ day was associated with a significantly higher relative risk (RR) for the development of hypertension compared with no use (RR 1.93, older women; RR 1.99, younger women). ${ }^{35}$ It is noteworthy that the risk of paracetamol was similar to that of traditional NSAID (RR 1.78, older women; RR 1.60 younger women). Another large, prospective cohort study ${ }^{36}$ by the same group showed that women who frequently ( $\geq 22$ days per months) consumed paracetamol had nearly the same risk of major cardiovascular events (non-fatal myocardial infarction, fatal coronary heart disease, non-fatal and fatal stroke) as traditional NSAID (RR 1.35, paracetamol; RR 1.44, traditional NSAID). Likewise, the use of paracetamol at 15 tablets or more per week conferred a risk of a cardiovascular event comparable to traditional NSAID (RR 1.68, paracetamol; RR 1.86, traditional NSAID). ${ }^{36}$ Key data of this study are summarised in table 1 .

These epidemiological data are supported by a recently published randomised, double-blind, placebo controlled, crossover study demonstrating that paracetamol induces a significant increase in ambulatory blood pressure in patients with coronary artery disease. ${ }^{37}$ In that study including 33 patients with coronary artery disease who received paracetamol $(1 \mathrm{~g}$ three times a day) on top of standard cardiovascular therapy for 2 weeks, treatment with paracetamol resulted in a significant increase in mean systolic (from $122.4 \pm 11.9$ to $125.3 \pm 12.0 \mathrm{~mm} \mathrm{Hg}$; $\mathrm{p}=0.02$ vs placebo) and diastolic (from $73.2 \pm 6.9$ to $75.4 \pm 7.9 \mathrm{~mm} \mathrm{Hg}$; $\mathrm{p}=0.02$ vs placebo) ambulatory blood pressures. The authors 
concluded that the use of paracetamol should be evaluated as rigorously as traditional NSAID and COX-2 inhibitors, particularly in patients at increased cardiovascular risk. However, attempts to clarify the mechanism of blood pressure elevation in the study were inclusive, making further investigations necessary.

\section{PLATELET DYSFUNCTION}

COX-1 initiates platelet aggregation by virtue of its product thromboxane $A_{2}$, which is rapidly converted into its inactive metabolite thromboxane $\mathrm{B}_{2}$. Therefore, blockade of COX-1 is the basis of the anti-aggregatory action of traditional NSAID on platelets. Paracetamol is a weak inhibitor of platelet COX-1 that elicits COX-1 suppression in clotting whole blood with $\mathrm{IC}_{50}$ values of $113.7 \mu \mathrm{mol} / 1$ (in vitro) and $105.2 \mu \mathrm{mol} / \mathrm{l}$ (ex vivo), respectively. ${ }^{11}$ Oral administration of $1 \mathrm{~g}$ paracetamol causing maximal plasma concentrations of $104.8 \mu \mathrm{mol} / 1$ results in an approximately $50 \%$ inhibition of COX-1 accordingly. ${ }^{11}$ Early investigations with this assay, which uses endogenous thrombin generated during a $1 \mathrm{~h}$ blood clotting as COX-1 stimulus, implied a greater than $95 \%$ COX-1 inhibition as necessary for suppression of the inhibition of platelet function. ${ }^{13}$ In line with this notion, paracetamol does not interfere with platelet function when given at single oral doses of $1 \mathrm{~g}^{38}$ or up to $1.95 \mathrm{~g} \cdot{ }^{39}$ It is noteworthy that the concentration of exogenous arachidonic acid used in several assays determines the potency of paracetamol to interfere with platelet COX-1. ${ }^{10}$ According to Boutaud et a $\left.\right|^{10}$ an inhibitory action of paracetamol on platelet COX-1 comparable to that obtained in clotting whole blood is obtained when using low concentrations $(0.5 \mu \mathrm{M})$ of exogenous arachidonic acid.

To the best of our knowledge there are no data on the impact of intravenous doses of paracetamol on ex-vivo thromboxane release determined by the above-mentioned whole blood assay, 111339 which uses blood clotting instead of exogenous arachidonic acid as the COX-1 stimulus. Apart from that, paracetamol has been shown to exert a reversible anti-aggregatory effect in healthy volunteers when used at higher parenteral doses. ${ }^{40} 41$ In one of those studies, paracetamol dose-dependently inhibited platelet aggregation stimulated with arachidonic acid, adenosine diphosphate or epinephrine. ${ }^{41}$ Following a 10-min infusion with paracetamol at 15, 22.5 and $30 \mathrm{mg} / \mathrm{kg}$, platelet aggregation triggered with $500 \mu \mathrm{M}$ arachidonic acid was significantly inhibited by $10 \%, 83 \%$ and $86 \%$ at corresponding paracetamol plasma concentrations of 124,199 and $259 \mu \mathrm{M}$, respectively. ${ }^{41}$ As expected, increasing the concentration of arachidonic acid counteracted this inhibition. ${ }^{41}$ The authors concluded that an anti-aggregatory action of paracetamol may become clinically significant in patients with intrinsic or drug-induced impairment of haemostasis. ${ }^{41}$ In another double blind, crossover volunteer study the combination of $30 \mathrm{mg} / \mathrm{kg}$ propacetamol (prodrug that is hydrolysed to $50 \%$ paracetamol) and $1.1 \mathrm{mg} / \mathrm{kg}$ diclofenac was shown to inhibit platelet function more than diclofenac alone. ${ }^{42}$ Referring to thromboxane $\mathrm{B}_{2}$ levels from platelets activated with $1 \mathrm{mM}$ arachidonic acid determined 5 and 90 min after administration, the combination reduced thromboxane $\mathrm{B}_{2}$ release to $1.3 \%$ and $10.6 \% \mathrm{com}$ pared with preinfusion levels $(100 \%)$, whereas diclofenac alone caused values of $1.6 \%$ and $44.1 \%$, respectively. ${ }^{42}$ In line with these data, the reversibility of platelet inhibition by diclofenac at 90 min was almost fully prevented when diclofenac was administered in combination with propacetamol. ${ }^{42}$ Again, the authors suggest to consider this interaction when assessing the balance between bleeding and thrombotic complications during and after surgery. In a subsequent in-vitro study an even synergistic increase of diclofenac's inhibitory action on platelet aggregation by paracetamol was confirmed. ${ }^{43}$

\section{GASTROINTESTINAL SIDE-EFFECTS}

Concerning paracetamol's impact on human gastric mucosal prostaglandin formation only a limited number of studies exist. Whereas paracetamol had no effect on prostaglandin synthesis on gastric mucosa when added in vitro, ${ }^{44}$ another study reports significant inhibitions of $\mathrm{PGE}_{2}$-like activity in the gastric mucosa of duodenal ulcer patients after the oral administration of paracetamol. ${ }^{45}$ Decreases in $\mathrm{PGE}_{2}$ levels by approximately $40 \%$ (fundus) and $60 \%$ (antrum) were observed following the administration of $2.5 \mathrm{~g}$ paracetamol given in divided $500 \mathrm{mg}$ doses during a single day. ${ }^{45}$ Although this inhibition was less pronounced when compared with $2.5 \mathrm{~g}$ aspirin and accompanied by only mild gastroscopic mucosal changes, ${ }^{45}$ the study points to the principal capacity of paracetamol to interfere with gastric prostaglandin synthesis. Accordingly, much more pronounced inhibitions are expected to occur following the administration of divided $1 \mathrm{~g}$ doses or extended dosing regimes ( $4 \mathrm{~g} /$ day).

The apparently favourable gastrointestinal tolerability of paracetamol compared with traditional NSAID is often cited with regard to a 7-day randomised trial, in which healthy volunteers receiving paracetamol $4 \mathrm{~g} /$ day showed no significant difference from the placebo group in terms of gastric mucosal injuries. ${ }^{46}$ However, this advantage is likely to be diminished when higher paracetamol doses are given for a longer period to patients. In this context it is worthy of note that gastroduodenal lesions are considered to develop as a consequence of persistent, moderate inhibition of mucosal COX-1, while bleeding complications occur as a result of transient, high-grade inhibition of COX-1. ${ }^{47}$ Unfortunately, no long-term endoscopy study has been performed with paracetamol so far. However, observational studies suggest that higher doses of paracetamol taken for a longer period of time may elicit a gastrointestinal risk profile similar to traditional NSAID. In the first of these studies, the group of Garcia-Rodriguez and Hernández-Díaz ${ }^{48}$ analysed upper gastrointestinal complications in almost 1 million patients receiving paracetamol and/or traditional NSAID during a 5-year investigation period. The RR for paracetamol showed a clear dose-dependence with an adjusted RR for paracetamol of 3.6 at doses greater than $2 \mathrm{~g}$. In addition, the combined administration of traditional NSAID and paracetamol was associated with an overadditive increase of RR. ${ }^{49}$ These results were supported by a recently published retrospective cohort study on 644183 old (>65 years) patients receiving paracetamol and/or traditional NSAID during a 6-year investigation period ${ }^{50}$ In that study the risk of hospitalisation due to gastrointestinal events (ulcer, perforation, bleeding in upper or lower gastrointestinal tract) was shown to be twice as high following the combined administration of paracetamol with traditional NSAID compared with the use of traditional NSAID alone (table 2). The authors explained this finding by paracetamol's additional COX-1 inhibition, which is plausible in view of data showing paracetamol to augment diclofenac's inhibitory action on platelet aggregation in a synergistic manner. ${ }^{43}$ The study by Rahme et a ${ }^{50}$ concludes with the recommendation to avoid the use of traditional NSAID in combination with paracetamol. Clearly, epidemiological studies that might include several confounding factors do not replace controlled trials. However, in this case they definitely refer to a dose-dependency of gastrointestinal toxicity by paracetamol, the long-term gastrointestinal impact of which should eventually be investigated in randomised studies including patients with osteoarthrosis. A first attempt in this 
Table 2 Risk of gastrointestinal hospitalisation (ulceration, perforation or bleeding in the upper or lower gastrointestinal tract) among older patients who received prescriptions for paracetamol, traditional NSAID or the combination of paracetamol and a traditional NSAID, either with or without a PPI

\begin{tabular}{lll}
\hline & Non-users of PPI & Users of PPI \\
\hline Paracetamol $\leq 3 \mathrm{~g} /$ day & Reference category $(1.00)$ & $0.95(0.81$ to 1.11$)$ \\
Paracetamol $>3 \mathrm{~g} /$ day & $1.20(1.03$ to 1.40$)$ & $1.16(0.94$ to 1.43$)$ \\
Paracetamol and traditional NSAID & $2.55(1.93$ to 3.28$)$ & $2.15(1.35$ to 3.40$)$ \\
Traditional NSAID & $1.63(1.44$ to 1.85$)$ & $1.07(0.82$ to 1.39$)$
\end{tabular}

Data are the results of a population-based retrospective cohort study ${ }^{50}$ including 644183 older patients (>65 years) who filled a prescription from either of these medications between 1998 and 2004. Follow-up ended at the first date of a

gastrointestinal hospitalisation, death or the end of the study period. Data are HR. Numbers in brackets are $95 \%$ Cl.

NSAID, non-steroidal anti-inflammatory drug; PPI, proton pump inhibitor.

direction has recently been published with a randomised, active controlled trial on 892 participants with chronic knee pain, most of them fulfilling the American College of Rheumatology criteria for knee osteoarthritis. ${ }^{51}$ On the basis of haemoglobin levels measured the authors state that paracetamol $3 \mathrm{~g} /$ day may cause similar degrees of blood loss as ibuprofen $1.2 \mathrm{mg} /$ day, and that the combination of the two appears to be additive, or even synergistic in terms of the number of individuals with a greater than $2 \mathrm{~g} / \mathrm{dl}$ decrease in haemoglobin. ${ }^{51}$ Although the clinical relevance of these decreases remains to be determined, the authors state that these investigational results challenge the belief that paracetamol is the treatment of choice based on an absent/lower risk of gastrointestinal complications compared with ibuprofen.

\section{ASPIRIN-INDUCED ASTHMA}

With respect to COX-1 inhibition by paracetamol, a thorough analysis of its side-effects on the respiratory tract seems likewise to be advised. Hypersensitivity to aspirin and other chemically unrelated traditional NSAID affects 5-20\% of patients with chronic asthma and an unknown fraction of patients with chronic urticaria-angioedema. These reactions appear to be caused by COX-1 inhibition, which in turn leads to activation of the lipoxygenase pathway and the production of cysteinyl leukotrienes that induce bronchospasm and nasal obstruction. Asthma patients who are intolerant to traditional NSAID produce low levels of bronchodilatory $\mathrm{PGE}_{2}$ (probably because of a lack of COX-2), have increased levels of leukotriene $\mathrm{C}_{4}$ synthase and reduced levels of metabolites (lipoxins) released through the transcellular metabolism of arachidonic acid. ${ }^{52}$ Whereas selective COX-2 inhibitors were well tolerated by aspirin-sensitive asthma patients in several re-exposure studies, patients with this pseudoallergic reaction show high cross sensitivities to traditional NSAID (ibuprofen, 98\%; naproxen, 100\%; diclofenac, $93 \%) .{ }^{53}$ On the other hand, an incidence of only $7 \%$ was observed among patients taking paracetamol. ${ }^{53}$ Although these data initially point to an advantage of the preferential COX-2 inhibitor paracetamol, a closer look shows that many studies using 500 or $650 \mathrm{mg}$ paracetamol for oral provocation (ie, doses not providing remarkable COX-1 inhibition) were included in this analysis. ${ }^{53}$ Remarkably, in one study $26 \%$ or $32 \%$ of the included patients developed bronchospasms following the administration of 1 or $1.5 \mathrm{~g}$ paracetamol, ${ }^{54}$ warranting further analyses in this respect. In accordance with the latter findings, recently proposed management strategies for patients with aspirin-induced asthma advise these patients to use paracetamol at doses of less than $1 \mathrm{~g} .{ }^{54}$

\section{CONCLUSION}

Preferential inhibition of COX-2 by paracetamol may explain clinical observations showing that paracetamol does not elicit a gastrointestinal toxicity comparable to traditional NSAID in endoscopy studies when administered at recommended doses for a few days only and does not inhibit platelet function when given at single oral doses up to $1.95 \mathrm{~g}$. Paracetamol's potency as a COX-2 inhibitor strongly depends on the oxidant/antioxidant status of the surrounding system. However, a pronounced COX-2 inhibition by paracetamol is expected to occur in the endothelium, possibly explaining the cardiovascular risk associated with the long-term use of this drug as shown in epidemiological studies. A careful analysis of paracetamol's cardiovascular risk in randomised studies is therefore strongly advised. In addition, epidemiological data imply an increased gastrointestinal risk of paracetamol when given at high doses for a prolonged time as well as when co-administered with traditional NSAID. Finally, paracetamol's fast elimination and consequent shortlived COX-2 inhibition should be considered to avoid overdosages leading to the well-known hepatotoxic side-effects of the drug.

Collectively, there are accumulating data raising concern over the presumed safety of paracetamol compared with traditional NSAID with respect to side-effects related to cyclooxygenase inhibition. A more sceptical awareness as well as a more critical research on this old drug is therefore strongly advised.

Contributors $\mathrm{BH}$ developed the concept, performed the literature search and wrote the article. KB added to drafting and literature.

Competing interests None.

Provenance and peer review Not commissioned; externally peer reviewed.

\section{REFERENCES}

1. Schnitzer TJ. Update of ACR guidelines for osteoarthritis: role of the coxibs. J Pain Symptom Manage 2002;23(4 Suppl):S24-30; discussion S31-4.

2. Botting RM. Mechanism of action of acetaminophen: is there a cyclooxygenase 3? Clin Infect Dis 2000;31(Suppl 5):S202-10.

3. Flower RJ, Vane JR. Inhibition of prostaglandin synthetase in brain explains the anti-pyretic activity of paracetamol (4-acetamidophenol). Nature 1972;240:410-11.

4. Graham GG, Scott KF. Mechanism of action of paracetamol. Am J Ther 2005; 12:46-55

5. Chandrasekharan NV, Dai H, Roos KL, et al. COX-3, a cyclooxygenase-1 variant inhibited by acetaminophen and other analgesic/antipyretic drugs: cloning, structure, and expression. Proc Natl Acad Sci U S A 2002;99:13926-31.

6. Kis B, Snipes JA, Busija DW. Acetaminophen and the cyclooxygenase-3 puzzle: sorting out facts, fictions, and uncertainties. J Pharmacol Exp Ther 2005; 315:1-7.

7. Loll PJ, Picot D, Ekabo 0, et al. Synthesis and use of iodinated nonsteroidal antiinflammatory drug analogs as crystallographic probes of the prostaglandin $\mathrm{H}_{2}$ synthase cyclooxygenase active site. Biochemistry 1996;35:7330-40.

8. Gierse JK, Koboldt CM, Walker MC, et al. Kinetic basis for selective inhibition of cyclo-oxygenases. Biochem J 1999;339:607-14.

9. Ouellet M, Percival MD. Mechanism of acetaminophen inhibition of cyclooxygenase isoforms. Arch Biochem Biophys 2001;387:273-80.

10. Boutaud 0, Aronoff DM, Richardson JH, et al. Determinants of the cellular specificity of acetaminophen as an inhibitor of prostaglandin $\mathrm{H}_{2}$ ) synthases. Proc Natl Acad Sci U S A 2002;99:7130-5.

11. Hinz B, Cheremina O, Brune K. Acetaminophen (paracetamol) is a selective cyclooxygenase-2 inhibitor in man. FASEB J 2008;22:383-90.

12. Huntjens DR, Danhof M, Della Pasqua OE. Pharmacokinetic-pharmacodynamic correlations and biomarkers in the development of COX-2 inhibitors. Rheumatology (Oxford) 2005:44:846-59.

13. Reilly IA, FitzGerald GA. Inhibition of thromboxane formation in vivo and ex vivo: implications for therapy with platelet inhibitory drugs. Blood 1987;69:180-6.

14. Halliwell B, Gutteridge JM. The antioxidants of human extracellular fluids. Arch Biochem Biophys 1990;280:1-8.

15. Lee YS, Kim H, Brahim JS, et al. Acetaminophen selectively suppresses peripheral prostaglandin E2 release and increases $\mathrm{COX}_{2}{ }_{2}$ gene expression in a clinical model of acute inflammation. Pain 2007;129:279-86.

16. Boardman PL, Hart FD. Clinical measurement of the anti-inflammatory effects of salicylates in rheumatoid arthritis. BMJ 1967;4:264-8. 
17. Ring EF, Collins AJ, Bacon PA, et al. Quantitation of thermography in arthritis using multi-isothermal analysis. II. Effect of nonsteroidal anti-inflammatory therapy on the thermographic index. Ann Rheum Dis 1974;33:353-6.

18. Seppälä $\mathbf{E}$, Nissilä $M$, Isomäki $H$, et al. Comparison of the effects of different anti-inflammatory drugs on synovial fluid prostanoid concentrations in patients with rheumatoid arthritis. Clin Rheumatol 1985;4:315-20.

19. Skjelbred $\mathbf{P}$, Løkken P. Paracetamol versus placebo: effects on post-operative course. Eur J Clin Pharmacol 1979;15:27-33.

20. Bjørnsson GA, Haanaes HR, Skoglund LA. A randomized, double-blind crossover trial of paracetamol $1000 \mathrm{mg}$ four times daily vs ibuprofen $600 \mathrm{mg}$ : effect on swelling and other postoperative events after third molar surgery. Br J Clin Pharmacol 2003;55:405-12.

21. Ferreira SH, Lorenzetti BB, Correa FM. Blockade of central and peripheral generation of prostaglandins explains the antialgic effect of aspirin like drugs. Pol J Pharmacol Pharm 1978;30:133-40

22. Honoré $\mathbf{P}$, Buritova J, Besson JM. Aspirin and acetaminophen reduced both Fos expression in rat lumbar spinal cord and inflammatory signs produced by carrageenin inflammation. Pain 1995;63:365-75.

23. Smith CJ, Zhang Y, Koboldt CM, et al. Pharmacological analysis of cyclooxygenase-1 in inflammation. Proc Natl Acad Sci U S A 1998;95:13313-18.

24. Cannon CP, Curtis SP, FitzGerald GA, et al. Cardiovascular outcomes with etoricoxib and diclofenac in patients with osteoarthritis and rheumatoid arthritis in the Multinational Etoricoxib and Diclofenac Arthritis Long-term (MEDAL) programme: a randomised comparison. Lancet 2006;368:1771-81.

25. Hinz B, Dormann H, Brune K. More pronounced inhibition of cyclooxygenase 2, increase in blood pressure, and reduction of heart rate by treatment with diclofenac compared with celecoxib and rofecoxib. Arthritis Rheum 2006;54:282-91.

26. O'Brien WF, Krammer J, O'Leary TD, et al. The effect of acetaminophen on prostacyclin production in pregnant women. Am J Obstet Gynecol 1993;168:1164-9.

27. Grèen K, Drvota V, Vesterqvist 0 . Pronounced reduction of in vivo prostacyclin synthesis in humans by acetaminophen (paracetamol). Prostaglandins 1989;37:311-15.

28. Walsh SW. Preeclampsia: an imbalance in placental prostacyclin and thromboxane production. Am J Obstet Gynecol 1985;152:335-40.

29. Noris M, Perico N, Remuzzi G. Mechanisms of disease: pre-eclampsia. Nat Clin Pract Nephrol 2005;1:98-114; quiz 120.

30. Zelop CM. Is it time to re-evaluate our use of acetaminophen in certain sub-groups of pregnant women? J Matern Fetal Neonatal Med 2008;21:761-2.

31. Rebordosa C, Zelop CM, Kogevinas M, et al. Use of acetaminophen during pregnancy and risk of preeclampsia, hypertensive and vascular disorders: a birth cohort study. J Matern Fetal Neonatal Med 2010;23:371-8.

32. McAdam BF, Catella-Lawson F, Mardini IA, et al. Systemic biosynthesis of prostacyclin by cyclooxygenase (COX)-2: the human pharmacology of a selective inhibitor of COX-2. Proc Natl Acad Sci U S A 1999:96:272-7.

33. Hinz B, Brune K. Can drug removals involving cyclooxygenase-2 inhibitors be avoided? A plea for human pharmacology. Trends Pharmacol Sci 2008;29:391-7.

34. García Rodríguez LA, Tacconelli S, Patrignani P. Role of dose potency in the prediction of risk of myocardial infarction associated with nonsteroidal antiinflammatory drugs in the general population. J Am Coll Cardiol 2008;52:1628-36.

35. Forman JP, Stampfer MJ, Curhan GC. Non-narcotic analgesic dose and risk of incident hypertension in US women. Hypertension 2005;46:500-7.
36. Chan AT, Manson JE, Albert CM, et al. Nonsteroidal antiinflammatory drugs, acetaminophen, and the risk of cardiovascular events. Circulation 2006:113:1578-87.

37. Sudano I, Flammer AJ, Périat D, et al. Acetaminophen increases blood pressure in patients with coronary artery disease. Circulation 2010:122:1789-96.

38. Mielke CH Jr. Comparative effects of aspirin and acetaminophen on hemostasis. Arch Intern Med 1981;141:305-10.

39. Catella-Lawson F, Reilly MP, Kapoor SC, et al. Cyclooxygenase inhibitors and the antiplatelet effects of aspirin. N Engl J Med 2001;345:1809-17.

40. Niemi TT, Backman JT, Syrjälä MT, et al. Platelet dysfunction after intravenous ketorolac or propacetamol. Acta Anaesthesiol Scand 2000;44:69-74.

41. Munsterhjelm E, Munsterhjelm NM, Niemi TT, et al. Dose-dependent inhibition of platelet function by acetaminophen in healthy volunteers. Anesthesiology 2005;103:712-17

42. Munsterhjelm E, Niemi TT, Syrjälä MT, et al. Propacetamol augments inhibition of platelet function by diclofenac in volunteers. Br J Anaesth 2003;91:357-62.

43. Munsterhjelm E, Niemi $\Pi$, Ylikorkala 0, et al. Characterization of inhibition of platelet function by paracetamol and its interaction with diclofenac in vitro. Acta Anaesthesiol Scand 2005;49:840-6.

44. Peskar BM. On the synthesis of prostaglandins by human gastric mucosa and its modification by drugs. Biochim Biophys Acta 1977;487:307-14.

45. Konturek SJ, Obtulowicz W, Sito E, et al. Distribution of prostaglandins in gastric and duodenal mucosa of healthy subjects and duodenal ulcer patients: effects of aspirin and paracetamol. Gut 1981;22:283-9.

46. Lanza FL, Codispoti JR, Nelson EB. An endoscopic comparison of gastroduodenal injury with over-the-counter doses of ketoprofen and acetaminophen. Am J Gastroenterol 1998;93:1051-4.

47. Patrono C, Patrignani P, García Rodríguez LA. Cyclooxygenase-selective inhibition of prostanoid formation: transducing biochemical selectivity into clinical read-outs. J Clin Invest 2001;108:7-13.

48. García Rodríguez LA, Hernández-Díaz S. Relative risk of upper gastrointestinal complications among users of acetaminophen and nonsteroidal anti-inflammatory drugs. Epidemiology 2001;12:570-6

49. Garcia Rodríguez LA, Hernández-Díaz S. The risk of upper gastrointestinal complications associated with nonsteroidal anti-inflammatory drugs, glucocorticoids, acetaminophen, and combinations of these agents. Arthritis Res 2001;3:98-101.

50. Rahme E, Barkun A, Nedjar H, et al. Hospitalizations for upper and lower Gl events associated with traditional NSAIDs and acetaminophen among the elderly in Quebec, Canada. Am J Gastroenterol 2008;103:872-82.

51. Doherty M, Hawkey C, Goulder M, et al. A randomised controlled trial of ibuprofen, paracetamol or a combination tablet of ibuprofen/paracetamol in community-derived people with knee pain. Ann Rheum Dis 2011;70:1534-41.

52. Picado C. Mechanisms of aspirin sensitivity. Curr Allergy Asthma Rep 2006:6:198-202.

53. Jenkins C, Costello J, Hodge L. Systematic review of prevalence of aspirin induced asthma and its implications for clinical practice. BMJ 2004;328:434.

54. Settipane RA, Schrank PJ, Simon RA, et al. Prevalence of cross-sensitivity with acetaminophen in aspirin-sensitive asthmatic subjects. J Allergy Clin Immunol 1995:96:480-5. 


\section{A RD Paracetamol and cyclooxygenase inhibition: is there a cause for concern?}

Burkhard Hinz and Kay Brune

Ann Rheum Dis 2012 71: 20-25 originally published online October 28, 2011

doi: 10.1136/ard.2011.200087

Updated information and services can be found at:

http://ard.bmj.com/content/71/1/20

These include:

References This article cites 54 articles, 19 of which you can access for free at: http://ard.bmj.com/content/71/1/20\#BIBL

Email alerting Receive free email alerts when new articles cite this article. Sign up in the service box at the top right corner of the online article.

\section{Notes}

To request permissions go to:

http://group.bmj.com/group/rights-licensing/permissions

To order reprints go to:

http://journals.bmj.com/cgi/reprintform

To subscribe to BMJ go to:

http://group.bmj.com/subscribe/ 